\title{
Investigating the association between fantasy proneness and emotional distress: the mediating role of cognitive coping strategies
}

Bacon, Alison

http://hdl.handle.net/10026.1/11861

10.1016/j.paid.2018.07.00307.003

Personality and Individual Differences

Elsevier

All content in PEARL is protected by copyright law. Author manuscripts are made available in accordance with publisher policies. Please cite only the published version using the details provided on the item record or document. In the absence of an open licence (e.g. Creative Commons), permissions for further reuse of content should be sought from the publisher or author. 
Published in:

Personality \& Individual Differences (2018) 135, 157-165.

DOI: https://doi.org/10.1016/j.paid.2018.07.003

Investigating the association between fantasy proneness and emotional distress: the mediating role of cognitive coping strategies

\author{
Alison M. Bacon \\ $\&$ \\ Jaysan J. Charlesford \\ School of Psychology \\ Plymouth University, UK
}

Corresponding author:

Dr Alison M. Bacon

School of Psychology

Plymouth University

Drake Circus

Plymouth PL4 8AA

Tel: 01752584805

Fax: 01752584808

Email: ambacon@plymouth.ac.uk 


\begin{abstract}
Fantasy proneness (FP; the tendency to immersion in imagination) is linked to psychopathology and suggested to be a maladaptive coping strategy. However, some evidence suggests it can be a positive trait. We examined whether the FP-emotional distress relationship is mediated by coping strategy. Participants completed the Depression, Anxiety and Stress Scale, the Cognitive Emotion Regulation Questionnaire measure of coping strategies, the Creative Experiences Questionnaire FP scale (Study $1 ; N=248$ ) and the newly developed Fantasy Questionnaire which measures fantasy across two subscales, creative and imaginative (Study 2; $N=208$ ). In Study 1, FP presented positive associations with emotional distress, with maladaptive coping strategies self-blame, rumination and catastrophizing, and with adaptive strategies positive refocussing, planning and positive reappraisal. Mediation indicated that self-blame and rumination partially accounted for the negative relationship between FP and distress, while positive refocussing ameliorated it. In Study 2, creative fantasy showed no relationship with distress, though imaginative fantasy was positively associated, with selfblame mediating the relationship. A tendency to fantasise can negatively influence psychological outcomes particularly in the presence of maladaptive coping. Our data support the suggestion that fantasy proneness is multi-componential and that not all aspects are linked to negative emotion.
\end{abstract}

Keywords: fantasy proneness; coping; depression; creative fantasy; imaginative fantasy 
The association between life stress and risk of depressive and anxiety disorders is well established (e.g. Hammen, 2005; Kendler, Karkowski, \& Prescott, 1999; Mitchell, Parker, Gladstone, Wilhelm, \& Austin, 2003; Pine, Cohen, Johnson \& Brook, 2002) and the strategies individuals use to cope with stressful events have received a good deal of research attention. There is evidence that certain personality traits can predispose to emotional distress and coping in a way which is maladaptive and can exacerbate distress and in the present studies we examine these associations in terms of fantasy proneness (FP) a trait which reflects the tendency to experience "deep, profound, and long-standing involvement in fantasy and imagination"' (Lynn \& Rhue, 1988, p.35).

FP is inherently linked to visualisation, imagery and absorption, the tendency to become immersed in vivid and compelling imaginings (Tellegen \& Atkinson, 1974). Some individuals can have fantasies so vivid that they can be hard to distinguish from reality (Horselenberg, Merckelbach, van Breukelen, \& Wessel, 2004; Merckelbach, 2004; Merckelbach, Horselenberg, \& Muris, 2001) and even when fantasies are themselves enjoyable, their frequency and uncontrollability can be distressing (Bigelsen \& Schupak, 2011; Schupak \& Rosenthal, 2009). The majority of research into FP has focused on its welldocumented association with psychopathology, particularly dissociative disorders.

Dissociation is a defensive coping style suggested to be a response to exceptionally traumatic events (Dell \& O’Neil, 2009) and to result in severe psychopathology (Gershuny and Thayer, 1999; Merckelbach, Campo, Hardy, \& Giesbrecht, 2005; Rauschenberg \& Lynn, 1995; Waldo, Merritt \& Davis, 2000). Fantasisers tend to report more dissociative experiences and weaker cognitive, affective, and attentional control than individual who are not fantasy-prone (Rauschenberg \& Lynn, 2003).

However, there is evidence that FP is not a unitary construct. Sanchez-Bernardos \& Avia (2004) identified three subcomponents fantasy vividness, fantasy to escape and make 
believe, in a sample of adolescents and suggested these serve different psychological functions. While all three were linked to Neuroticism, a trait which reflects high vulnerability to stress, anxiety, depression and impulsivity in adults and depression and low self-esteem in adolescents (Bagby, Joffe, Parker, Kalemba, \& Harkness, 1995), only fantasy to escape from an unpleasant reality was interpreted as maladaptive (Sanchez-Bernardos \& Avia, 2004). Klinger, Henning and Janssen (2009) identified two components to FP: one reflected imaginativeness, enjoyable make-believe and daydreaming, while the other component reflected vivid, compelling mental imagery and parapsychological beliefs. Only this second component was related to psychological disorders. Other evidence has suggested that dissociation arises more from the nature of trauma than a tendency to fantasy (Dalenberg et al, 2012; Kluemper \& Dalenberg, 2014). Certainly, some degree of fantasising is a fairly universal part of normative emotional functioning (Eisen \& Lynn, 2001; Mason et al., 2007) and is also associated with everyday dissociative experiences (such as daydreaming and lapses in attention) which are common in response to stressful events or as an escape from boredom (Muris, Merckelbach \& Peters, 2003; Ross, Joshi \& Currie, 1991).

Moreover, there is considerable evidence that higher levels of fantasizing can be related to mood disorders in general non-clinical and some have suggested that fantasy can be adaptive in coping with stressful events. Smith and Mathur (2009) found that highly imaginative and fantasy-prone children tend to have effective coping skills and the ability to regulate their emotions. There is also evidence for what has been termed sustaining fantasy (Greenwald \& Harder, 1995, 1997) where fantasy is used as a conscious coping strategy, allowing for a welcome break from anxiety and the need to focus on stressful events. FP is certainly associated with everyday experiences such as daydreaming and lapses in attention. These are common in response to stress or as an escape from boredom but do not present a clinical level of dissociation (Muris et al., 2003; Ross et al., 1991; Sánchez-Bernardos and 
Avia, 2004). Overall, FP is a complex construct and, amidst equivocal results regarding the relationship between FP and emotional wellbeing, further research is needed. In the present studies, we examine FP conceptualised both in its more traditional sense of dissociative imagination (Study 1) and as a positive attribute (Study 2), and its relationship with emotional distress and coping strategies.

Coping refers to the use of conscious and volitional cognitive and behavioural strategies to regulate emotions and manage demands in response to stress (e.g. Folkman, Lazarus, Dunkel-Schetter, DeLongis \& Gruen, 1986; Folkman \& Moskowitz, 2004; Lazarus and Folkman, 1984). Some coping strategies are known to be adaptive, supporting problemsolving and associated decreases in emotional distress (e.g., Connor-Smith \& Compas, 2004). Conversely maladaptive strategies result in unsuccessful coping and can exacerbate distress, for instance rumination (focus on negative and pessimistic thoughts) is strongly predictive of depression (Nolen-Hoeksema, 1991). Coping is initiated when our appraisal of an event indicates that a personally valued goal or circumstance is threatened, so one of the first tasks in adaptive coping is to regulate the often intense emotions associated with such appraisals (Folkman \& Moskowitz, 2004). Garnefski, Kraaij, and Spinhoven $(2001,2002)$ have identified nine distinct cognitive coping strategies which support the regulation of emotion and it is this aspect of coping which is the focus of the present study. Five strategies are classed as adaptive: Putting into Perspective (emphasising severity in relation to worse possibilities), Positive Refocusing (thinking about more joyful and pleasant issues); Positive Reappraisal (finding a positive meaning in terms of personal growth), Acceptance (accepting and resigning to what has happened) and Planning (thinking about how to handle the situation proactively). Four other strategies can be classed as maladaptive: Self-and-other blame (putting blame for the event on the self or another person respectively), Rumination (repeatedly dwelling on feelings and thoughts associated with the negative event) and 
Catastrophizing (emphasizing the terror and extremity of the experience). Research has supported these classifications, and the potential for positive or negative emotional outcomes respectively, across a range of applied health settings, including identification of targets for intervention (e.g. Garnefski \& Kraaij, 2012; Kraaij \& Garnefski, 2015; Garnefski et al., 2013).

The role of fantasy in these cognitive coping processes has not previously been explored and it is possible that FP may contribute to both adaptive strategies for instance, positive refocussing or planning ahead, or maladaptive strategies such as rumination. This could mean that FP could support either a positive or negative emotional outcome. Studies typically employ measures such as the Creative Experiences Questionnaire (CEQ; Merckelbach et al., 2001) which assesses aspects of fantasy closely linked to dissociation and other disorders. Recently however, Weibel, Martarelli, Haberli and Mast (2017) highlighted the more positive connotations of fantasy, such as its associations with creativity (Barrett, 2010) and theory of mind (Taylor \& Carlson, 1997). Weibel et al. (2017) developed a new measure, The Fantasy Questionnaire, which assesses individual differences in the propensity to positive, adaptive non-clinical fantasy. In the present two studies, we examine the associations between FP, emotional distress and coping, firstly in terms of fantasy as measured by the CEQ and then, in Study 2, in terms of Weibel et al.'s more positive conceptualisation.

\section{Study 1}

In general terms, FP and the use of maladaptive cognitive coping strategies have both been associated with higher levels of emotional distress. Adaptive strategies however present a negative relationship with distress. In Study 1, we anticipated that scores on the CEQ measure of FP and emotional distress would be positively associated. In terms of Garnefski et al.'s (2001) model of cognitive coping, we proposed that FP may support effective emotion regulatory strategies such as imagining more pleasant things (Positive Refocusing) and 
alternative perspectives (Putting into Perspective; Positive Reappraisal). Conversely, FP may support less adaptive thinking by strengthening the distressing effect of rumination or catastrophizing. However, there is some evidence that some forms of rumination can play a positive role in regulating emotion. What has been termed "intellectual self-reflection" or "pondering" defines a more general self-reflective tendency to think about and analyse one's feelings and associated life events. It is shown to share common variance with negative rumination but is not correlated with depression (Siegle, Moore \& Thase, 2004; Teasdale \& Green, 2004). Nolen-Hoeksema, Wisko and Lyubomirsk (2008) discuss this in the context of self-regulatory theories which suggest that rumination on the perceived discrepancy between a desired state and actual state is adaptive because it leads to a resolution, either by triggering problem-solving action or the abandonment of an unrealistic desired state. Furthermore, Luminet, and Zech (2000) discussed how people can voluntarily develop ruminations about positive events and this self-maintained process supports emotion regulation by increasing positive affect. In the present context, we expect FP and negative emotions to be positively associated. If that relationship is mediated such that an alternative path via rumination results in ales negative outcomes, this would suggest the presence of this type of adaptive reflection.

\section{Participants}

Two hundred and fifty four undergraduate psychology students took part in return for course credit. Of these, six did not complete all of the measures and were removed from the sample prior to analysis. Hence our final sample comprised 248 participants, 154 females and 94 males $\left(M^{a g e}=20.94, S D=3.92\right)$. As we wanted to examine effects in a non-clinical population, we requested that participants have no current formal diagnosis of psychological disorder. They were also asked to self-declare this to be the case before beginning the study. A sample size of at least 200 is recommended to obtain a medium effect size in regression analysis with 11 predictor variables (Miles \& Shevlin, 2000). 


\section{Materials and Procedures}

Ethical approval for both studies was obtained from the authors' university Faculty Ethics Committee. All participants completed the following measures, in the same order. The questionnaires were presented online and accessed via a web link which was emailed to students who volunteered to take part. The presentation and response format did not differ from the traditional paper versions of the questionnaires in any other respect.

The Creative Experiences Questionnaire (CEQ: Merckelbach et al., 2001) is a dichotomous measure of fantasy proneness comprising 25 items, for example, "My fantasies are so vivid that they are like a good movie". "Yes" responses were summed to yield a total CEQ score with good internal consistency $(\alpha=.75)$.

Depression, Anxiety and Stress Scale (DASS; Lovibond \& Lovibond, 2002). The DASS comprises three 7-item scales to measure emotional distress: depression, anxiety and stress, specifically. It has a robust factor structure and high levels of reliability with nonclinical samples (Crawford \& Henry, 2003). Items present descriptions of affective symptoms, for example: "I couldn't seem to experience any positive feeling at all" (depression), "I was worried about situations where I might panic and make a fool of myself" (anxiety), and "I found it hard to wind down" (stress). Participants rated the extent to which they have experienced each symptom over the past week on a scale from 0 - Not at all to 3 -Most of the time. Scores for each emotional state were computed by summing responses from the items in each subscale and multiplying by 2 - hence maximum score for each scale was 42 , with higher scores indicating higher levels of emotional distress. Each scale showed good internal consistency with the present sample (depression $\alpha=.80$, anxiety $\alpha=.75$, stress $\alpha=.76$ ).

Cognitive Emotion Regulation Questionnaire (CERQ; Garnefski, et al, 2001). The CERQ measures the nine distinct cognitive emotion regulation strategies, defined previously. Each is measured via a subscale of four items reflecting what individuals may think after 
experiencing a stressful or threatening event. Participants respond to each CERQ item on a scale ranging from 1 (almost never) to 5 (almost always). A subscale score is obtained by summing responses to the four items, hence the maximum score is 20 . The higher the subscale score, the more that specific cognitive strategy is used. The subscales showed adequate reliability: self-blame $\alpha=0.69$, acceptance $\alpha=0.75$, rumination $\alpha=0.89$, positive refocussing $\alpha=0.78$, planning $\alpha=0.82$, positive reappraisal $\alpha=0.69$, putting into perspective $\alpha=0.84$, catastrophizing $\alpha=0.68$, other-blame $\alpha=0.79$.

Negative life events: following Garnefski, Teerds, Kraaij, Legerstee, and Van den Kommer (2004) participants completed a 12-item checklist which presented a series of events: divorce of parents and/or self; long-lasting and/or severe physical or mental illness of self and/or significant others; death of a spouse and/or significant others; attempted suicide of self and/or significant others; violence; abuse of drugs and/or alcohol within family and/or relationship; unwanted pregnancy; having been victim of crime; accident; sexual abuse and/or physical abuse (self). Participants were asked simply to indicate whether or not they had experienced each event. The main function of this was to control for the influence of number of negative life events experienced on emotion.

\section{Data Analysis}

Our aim was to examine whether the association between FP and negative emotions was influenced by coping strategy. Therefore, we first computed partial correlations between these variables, controlling for the potential effects of sex and number of negative life events experienced. Following this, regression analysis was conducted with emotional distress as the dependent variable, in order to determine whether variance in this factor was accounted for by coping strategies, over and above that explained by FP. Again, sex and events were included in the model as covariates. These statistics were computed using SPSS version 23. Finally, to test the influence of coping strategies, we conducted moderation and mediation analysis using 
the PROCESS procedure (Hayes, 2018). PROCESS is a freely-available macro for SPSS which integrates tools for mediation and moderation analysis into a single, user-friendly command file.

Table 1.

Descriptive statistics for all measures in Study 1.

\begin{tabular}{lcc}
\hline & Mean & SD \\
\hline Negative life events & 2.35 & 1.84 \\
Emotional distress & 12.55 & 4.21 \\
FP & 10.26 & 4.22 \\
Acceptance & 13.34 & 2.83 \\
Positive refocusing & 9.74 & 3.43 \\
Refocus on planning & 12.72 & 3.48 \\
Positive Reappraisal & 12.49 & 4.12 \\
Put into perspective & 12.12 & 3.84 \\
Self-blame & 10.71 & 3.14 \\
Rumination & 12.40 & 3.34 \\
Catastrophizing & 9.04 & 2.94 \\
Other-blame & 8.74 & 2.94 \\
\hline
\end{tabular}

\section{Results}

Table 1 presents descriptive statistics. Depression, anxiety and stress scores were intercorrelated ( $\mathrm{r}>.65$ in every case) and showed similar correlations with the other variables. Therefore, in line with previous research (Bacon, Walsh \& Martin, 2013; Lovibond \& Lovibond, 2002) we calculated the mean of the three scores to develop an overall emotional distress score. All variables were normally distributed with the exception of negative life events which was positively skewed. However, this was a covariate only and the data was included in analysis with no transformation. 
Table 2 presents partial correlations between measures, controlling for number of reported negative life events and sex (sex differences in use of the nine emotion regulation strategies have been reported, Garnefski et al, 2004). As Table 2 shows, FP (CEQ score) was positively and significantly correlated with emotional distress. FP also showed positive and significant relationships with all maladaptive strategies except Other-blame. However, it also showed similar correlations with adaptive strategies, also significant except for that with Putting in perspective. Emotional distress was positively associated with maladaptive strategies except for Other-blame, and presented modest negative associations with adaptive approaches Positive refocussing, Positive reappraisal and Putting in perspective. Emotional distress also presented a somewhat anomalous significant positive association with Acceptance. Previous work has also found Acceptance to correlate with negative behaviours and emotions, and suggested that its adaptive status requires re-examination and scores be interpreted with caution (Martin \& Dahlen, 2005). As such, we omitted Acceptance from the remainder of our analysis. 
Table 2. Partial correlations between measures controlling for sex and number of reported negative life events in Study 1.

\begin{tabular}{|c|c|c|c|c|c|c|c|c|c|c|c|}
\hline & & 1 & 2 & 3 & 4 & 5 & 6 & 7 & 8 & 9 & 10 \\
\hline 1 & Fantasy proneness & - & & & & & & & & & \\
\hline 2 & Distress & $.36 * *$ & & & & & & & & & \\
\hline 3 & Self-blame & $.27 * *$ & $.47 * *$ & & & & & & & & \\
\hline 4 & Rumination & $.37 * *$ & $.45^{* *}$ & $.61 * *$ & & & & & & & \\
\hline 5 & Catastrophizing & $.15^{*}$ & $.27 * *$ & $.43^{* *}$ & $.63 * *$ & & & & & & \\
\hline 6 & Other-blame & -.08 & -.01 & .02 & .06 & $.36 * *$ & & & & & \\
\hline 7 & Acceptance & $.18 *$ & $.15^{*}$ & $.17 *$ & $.19 *$ & .04 & .03 & & & & \\
\hline 8 & Positive refocussing & $.42 * *$ & -.11 & .01 & $.25^{* *}$ & .06 & -.04 & $.19 *$ & & & \\
\hline 9 & Refocus on planning & $.26 * *$ & .02 & .04 & $.20 *$ & -.07 & .12 & $.35^{* *}$ & $.37 * *$ & & \\
\hline 10 & Positive reappraisal & $.15 *$ & $-.15^{*}$ & -.11 & -.05 & $-.20 *$ & -.07 & $.25^{* *}$ & $.40 * *$ & $.62 * *$ & \\
\hline 11 & Put in perspective & .11 & $-.17 *$ & $-.20 *$ & -.12 & $-.30 * *$ & -.10 & $.24 * *$ & $.42 * *$ & $.35^{* *}$ & $.61 * *$ \\
\hline
\end{tabular}

$* \mathrm{p}<.05 ; * * \mathrm{p}<.001$ 
Given our á priori predictions, we used emotional distress as the dependent variable in regression analysis. We entered FP and the two covariates (sex and number of reported negative life events) at stage 1 , and the CERQ coping strategies at stage 2, see Table 3.

Table 3. Results of linear regression analysis on emotional distress

\begin{tabular}{|c|c|c|c|c|c|c|}
\hline & & \multirow[b]{2}{*}{$\beta$} & \multirow[b]{2}{*}{$\mathrm{t}$} & \multirow[b]{2}{*}{ Sig. } & \multicolumn{2}{|c|}{$\begin{array}{c}95 \% \text { Confidence } \\
\text { Interval }\end{array}$} \\
\hline & & & & & Lower & Upper \\
\hline \multirow[t]{3}{*}{1.} & Sex & -.08 & -1.34 & .18 & -1.74 & .33 \\
\hline & Events & .14 & 2.28 & .02 & .05 & .60 \\
\hline & $\mathrm{FP}$ & .36 & 5.69 & $<.001$ & .23 & .48 \\
\hline \multirow[t]{11}{*}{2.} & Sex & -.09 & -1.50 & .14 & -1.70 & .23 \\
\hline & Events & .13 & 2.15 & .03 & .02 & .55 \\
\hline & $\mathrm{FP}$ & .32 & 4.98 & $<.001$ & .19 & .44 \\
\hline & Self-blame & .24 & 3.48 & .001 & .14 & .51 \\
\hline & Rumination & .25 & 2.82 & .005 & .10 & .54 \\
\hline & Catastrophizing & -.02 & -.23 & .82 & -.26 & .20 \\
\hline & Other-blame & -.01 & -.19 & .85 & -.19 & .16 \\
\hline & Positive refocussing & -.28 & -4.06 & $<.001$ & -.51 & -.18 \\
\hline & Refocus on planning & .01 & .18 & .86 & -.16 & .20 \\
\hline & Positive reappraisal & -.08 & -.99 & .32 & -.24 & .08 \\
\hline & Put in perspective & .06 & .77 & .44 & -.09 & .22 \\
\hline
\end{tabular}

The model at stage 1 accounted for $16 \%$ variance in emotional distress $\left(A d j . R^{2}=.16\right)$ with FP an independent predictor. When the coping strategies were added at stage 2, a further $24 \%$ variance in distress was accounted for $\left(\operatorname{Adj} . R^{2}=.40 ; F\right.$ change $(8,215)=10.17, p$ $<.001)$. Self-blame, Rumination and Positive refocussing all shared independent levels of variance with emotional distress. FP remained an independent predictor, though the values shown in Table 3 indicate a partial mediating effect when coping strategies were added to the 
model. Figure 1 presents the outcomes and Table 4 the 95\% confidence intervals for each indirect effect. As these indicate, one adaptive strategy, positive refocussing, and two maladaptive strategies, self-blame and rumination, significantly mediated the link between FP and emotional distress.

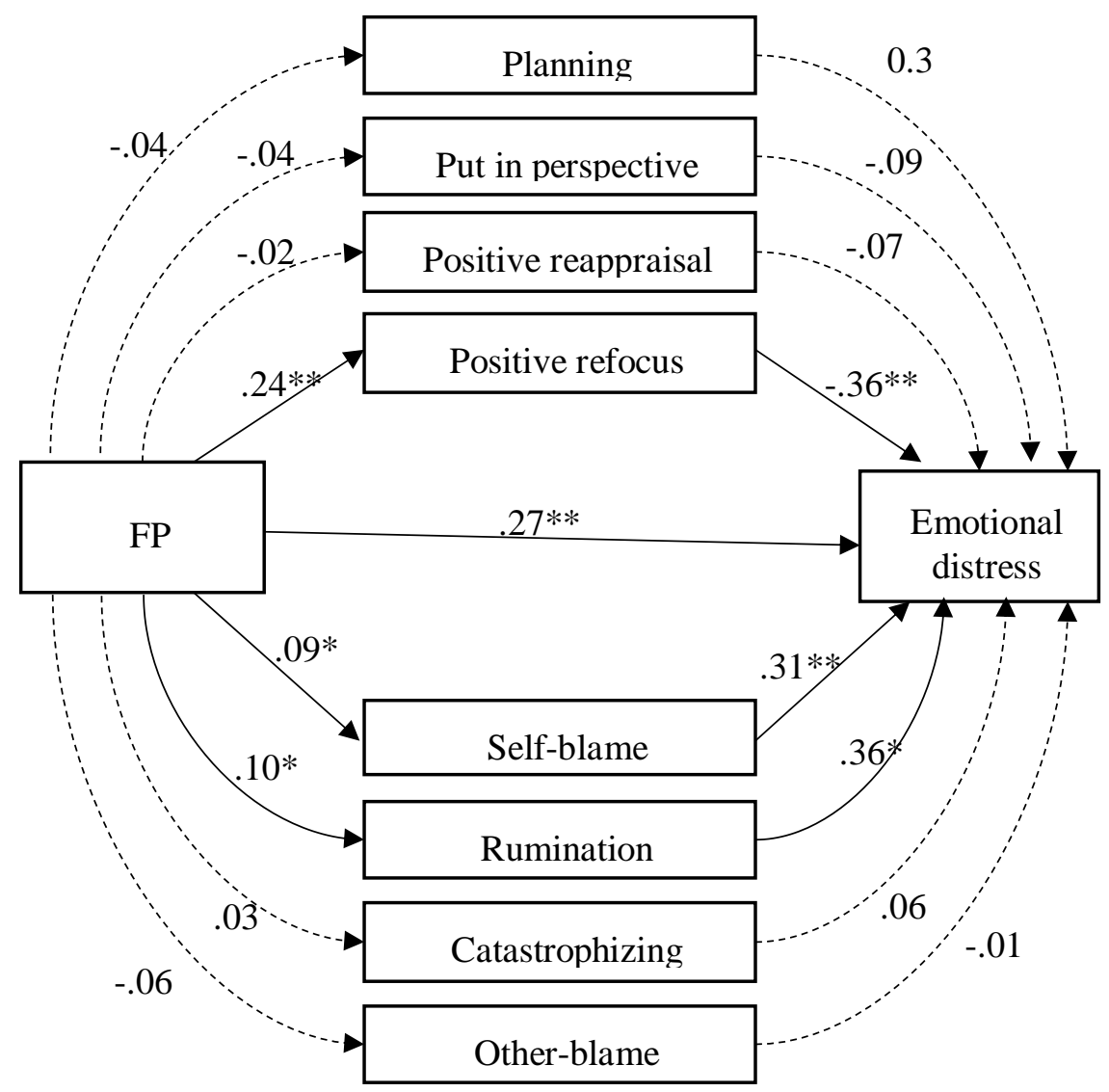

Figure 1. Outcome of tests for the mediation by coping strategy on effects of FP on emotional distress. Dashed lines indicate non-significant effects. Coefficients shown are unstandardized. $* p<.05 ; * * p<.01$ 
Table 4. Mediating effects of coping strategies on the association between FP and emotional distress

\begin{tabular}{llccc}
\hline & & Indirect effect & \multicolumn{2}{c}{$95 \%$ CI } \\
\multirow{3}{*}{ Adaptive strategies } & Unstandardized B & lower & upper \\
\cline { 2 - 5 } & Ptrategy & -.09 & -.15 & -.04 \\
& Positive refocussing & .002 & -.01 & .03 \\
& Put into perspective & -.004 & -.03 & .01 \\
& Planning & .002 & -.01 & .03 \\
Maladaptive strategies & Self-blame & & & \\
& Rumination & .03 & .004 & .08 \\
& Catastrophizing & .04 & .01 & .08 \\
& Other-blame & .002 & -.004 & .02 \\
& & .001 & -.01 & .02 \\
\hline
\end{tabular}

\section{Discussion}

This is the first study to directly test the relationship between fantasy proneness and emotional distress and to examine how specific coping strategies might influence this relationship. Firstly, our analyses suggest that FP and coping can independently account for variance in emotional distress. Secondly, certain coping strategies (rumination, self-blame and positive refocussing) significantly mediated the link between FP and distress. Rumination and self-blame have consistently been linked to emotional distress and our study indicated an indirect effect of FP on distress through use of these strategies. The indirect effect via Positive refocussing however was negative, suggesting that use of this strategy may reduce negative mood.

Initially, we highlighted the possibility that FP might support adaptive coping particularly given Smith and Mather's (2009) findings that children who are fantasy prone cope effectively. Plus, there is evidence that some forms of rumination can play a positive role in regulating emotion (Armey, et al., 2000). Although rumination mediated the positive association between FP and negative emotions, the indirect effect was also positive suggesting that as rumination increases, negative mood will also increase. Nevertheless, we do not 
discount the possibility that FP may support adaptive pondering, rather than maladaptive rumination, in some circumstances or for some individuals. Interestingly, as Table 2 shows, rumination was positively correlated with Positive Refocussing and Refocus on Planning. The relationships are moderate, but significant, and suggest a possible overlap between the components. Further research might usefully examine the role that FP can play in rumination. However, we suggest that such research employ a specific rumination scale together with measures of self-reflection as the four-item CERQ subscale used here may lack the breadth to truly capture the nature of rumination.

Alternatively, if FP is multi-componential, some aspects might be more closely linked with rumination than others. We did observe some adaptive effects of FP in conjunction with Positive refocussing whereby a negative indirect effect was observed suggesting that when fantasisers adopt this strategy the likelihood of a distressing outcome is reduced. Positive refocussing involves thinking of other, more pleasant, matters instead of the actual negative situation in hand and Nolen-Hoeksema (1987) suggested that one way in which the strategy is effective in regulating emotional distress is because it involves an element of distraction. Fantasy can also serve this function (Muris, et al, 2003). However, Garnefski, van den Kommer, et al. (2002) suggest that positive refocussing could also be considered a form of avoidance. Avoidance is a core mechanism in the development and maintenance of emotional distress and can diminish the number of positive appraisals of everyday events as well as mediating the effects of healthy coping on mood (Kashdan, Barrios, Forsyth, \& Steger, 2006). Furthermore, we also observed a mediating effect of Self-blame and this strategy also can be conceptualised positively. Causal attributions are a way to deal with stress and if individuals blame themselves they may believe they can change in order to influence the future, a potentially adaptive way of using self-blame in coping, leading to positive behaviour change and higher perceived control. Given this, together with evidence for fantasy as a dissociative 
experience, and alongside our present data, again it would seem that FP (or possibly different components of it) can involve adaptive and maladaptive processes.

\section{Study 2}

Study 1 presented some useful additions to current knowledge regarding the link between FP and distress. However, the CEQ tests for FP as a unitary concept and does not allow for examination of possible subfactors. Given that fantasy can sometimes be adaptive, it is possible that only certain aspects of fantasising are actually linked to distress and the relationships with coping may also differ. In Study 2, we employ an alternative and newly developed measure of FP to address this question. Weibel et al. (2017) highlighted how FP measures such as the CEQ were developed primarily for use in the investigation of dissociative disorders and pseudomemories and tend to ignore the more functional aspects of fantasising. They formulated FP as a positive and adaptive trait which supports creativity and everyday cognitive activities such as counterfactual thinking, representation, and metacognition. Weibel et al. draw on research which has suggested that fantasy is a requisite for goal-oriented behaviours and complex problem-solving and that because it can reflect on interpersonal behaviour, FP can be intrinsic to the experience of empathy (Barrett, 2010). They developed and validated a new questionnaire to measure individual differences in fantasising across two subscales: Creative fantasy (CF; the activity of using fantasy to create new ideas) and Imaginative fantasy (IF; the activity of vividly imagining and ease of becoming absorbed in images and daydreams). In Study 2, we wanted to test the role that these two supposedly positive aspects of fantasising might play in coping. Weibel et al. present no evidence of relationships between these factors and emotions, but if they are indeed both adaptive forms of fantasising (as Weibel et al., 2017 claim) we would expect scores to be negatively associated with emotional distress and maladaptive coping, but positively with 
adaptive strategies (Prediction1). However, Weibel et al.'s definition of Imaginative fantasy is similar to descriptions of original concept FP as measured in the CEQ (e.g. Lynn \& Rhue, 1988; Merckelbach et al., 2005). It also reflects exceptionally vivid imagery, identified as a potentially pathological aspect of FP by Klinger et al. (2009). As such, an alternative hypothesis is that IF (but not CF) will be positively associated with emotional distress and maladaptive coping (Prediction 2). In Study 2, we replicated the procedures of the first study, but examined FP as conceptualised by Weibel et al. (2017). We tested the predictions described above to examine whether $\mathrm{CF}$ and IF are as adaptive as claimed and whether coping strategies would mediate links with emotional distress.

\section{Participants}

Two hundred and eighteen students participated in return for course credit. Ten participants failed to complete at least one questionnaire and were therefore removed from the sample before analysis. The final sample $(N=208)$ comprised 178 females, 30 males; $M_{\text {age }}=$ 20.97, $S D=4.09$. None self-reported a diagnosis of any psychological disorder when requested. None had taken part in Study 1. As in Study 1, sample size was determined by the type of analysis planned (Miles \& Shevlin, 2000).

\section{Materials and Procedures}

Study 2 measures mirrored those for Study 1 except that instead of the CEQ, participants completed the Fantasy Questionnaire (Weibel et al, 2017). This 27-item scale assesses trait fantasy proneness across two subscales. Imaginative fantasy (IF; 16 items) reflects a tendency to vivid imagination and absorption in images and daydreams (e.g. My daydreams are often stimulating and rewarding), and Creative fantasy (CF; 11 items), the tendency to use fantasy to create new ideas (e.g. A really original idea sometimes develops from a really fantastic dream). Participants indicate how applicable each item is to them on a 
scale from 1 (strongly disagree) to 5 (strongly agree). Both subscales showed good reliability with the present sample, IF $\alpha=0.89$ and CF $\alpha=0.91$.

CERQ subscales also showed good reliability in this study: self-blame $\alpha=0.87$, rumination $\alpha=0.77$, catastrophizing $\alpha=0.76$, other-blame $\alpha=0.82$, acceptance $\alpha=0.75$, positive refocussing $\alpha=0.85$, positive reappraisal $\alpha=0.84$, Planning $\alpha=0.82$ and putting into perspective $\alpha=0.79$. Again we computed the mean DASS score as an overall measure of emotional distress $(\alpha=0.93)$. Participants also completed the negative life events measure as previously.

Data analysis replicated that in Study 1.

\section{Results}

Table 5 presents descriptive statistics for all measures. As in Study 1, an overall Emotional distress score was computed as the mean of the three DASS scores. Variables were normally distributed with the exception of negative life events which were again positively skewed. The level of emotional distress reported was lower than in Study 1. 
Table 5. Descriptive statistics for all measures in Study 2

\begin{tabular}{lcc}
\hline & Mean & SD \\
\hline Negative life events & 3.82 & 2.47 \\
Emotional distress & 8.56 & 4.02 \\
Creative Fantasy (CF) & 28.18 & 8.62 \\
Imaginative fantasy (IF) & 46.96 & 11.42 \\
Acceptance & 12.92 & 3.14 \\
Positive refocusing & 9.44 & 3.53 \\
Refocus on planning & 11.51 & 3.61 \\
Positive Reappraisal & 11.38 & 3.82 \\
Put into perspective & 12.45 & 3.56 \\
Self-blame & 11.88 & 3.75 \\
Rumination & 13.12 & 3.39 \\
Catastrophizing & 9.56 & 3.44 \\
Other-blame & 8.56 & 2.94 \\
\hline
\end{tabular}

Table 6 shows partial correlations between the two fantasy scale scores, coping strategy scores and emotional distress, controlling for sex and number of reported life events. 
Table 6. Partial correlations controlling for sex and life events in Study 2.

\begin{tabular}{|c|c|c|c|c|c|c|c|c|c|c|c|}
\hline & 1 & 2 & 3 & 4 & 5 & 6 & 7 & 8 & 9 & 10 & 11 \\
\hline $1 \mathrm{CF}$ & - & & & & & & & & & & \\
\hline $2 \mathrm{IF}$ & $.73 * *$ & & & & & & & & & & \\
\hline 3 Distress & .02 & $.23 * *$ & & & & & & & & & \\
\hline 4 Self-blame & $.26 * *$ & $.35 * *$ & $.37 * *$ & & & & & & & & \\
\hline 5 Rumination & $.21 * *$ & $.31 * *$ & $.35 * *$ & $.61 * *$ & & & & & & & \\
\hline 6 Catastrophizing & $.14^{*}$ & $.14^{*}$ & $.32 * *$ & $.36 * *$ & $.49 * *$ & & & & & & \\
\hline 7 Other-blame & .09 & .06 & $.32 * *$ & .11 & $.30 * *$ & $.45^{* *}$ & & & & & \\
\hline 8 Acceptance & $.24 * *$ & $.18^{*}$ & $.15^{*}$ & $.45^{* *}$ & $.56 * *$ & $.22 * *$ & $.17^{*}$ & & & & \\
\hline 9 Positive refocussing & $.24 * *$ & $.18 *$ & $-.17 *$ & -.07 & .05 & -.07 & .01 & $.28 * *$ & & & \\
\hline 10 Planning & $.32 * *$ & $.17 *$ & $-.13 *$ & .06 & $.21 * *$ & .13 & .08 & $.43 * *$ & $.65^{* *}$ & & \\
\hline 11Positive reappraisal & $.30 * *$ & .11 & -.10 & -.09 & .02 & -.06 & .07 & $.38 * *$ & $.62^{* *}$ & $.72 * *$ & \\
\hline 12 Put into perspective & $.14^{*}$ & .09 & -.08 & .00 & $.17 *$ & $-.16^{*}$ & -.04 & $.43 * *$ & $.49 * *$ & $.57 * *$ & $.65^{* *}$ \\
\hline
\end{tabular}


The two forms of fantasising were intercorrelated (Weibel et al, 2017 also reported this to be the case), though, only IF was positively associated with emotional distress. Of the adaptive strategies, acceptance, planning and positive refocussing were all positively linked to both $\mathrm{CF}$ and IF, and positive reappraisal and putting into perspective with CF only. With the exception of Other-blame, maladaptive strategies were positively associated with both CF and IF. As in Study 1, all four maladaptive coping strategies were positively and significantly associated with distress. Refocussing and planning showed significant negative relationships with distress. As in Study 1, acceptance showed a positive relationship with distress despite being a supposedly adaptive approach and again we left acceptance out from the remainder of the analyses. Some of the intercorrelations between coping strategy scores differed from those in Study 1, two significantly so; catastrophizing and rumination (Fisher's $z=2.17, p=.03$ ) and between putting into perspective and planning (Fisher's $z=2.98, p=.002$ ). However, none varied in their valence and the overall trends were very similar.

We computed two separate regression analyses on emotional distress, once with each type of fantasy. Table 7 shows the results. Imaginative fantasy shared positive variance with distress and introduction of the coping strategies to the model appeared to partially mediate the effect. Strategies self and other blame (positive) and refocus on planning (negative) were independent predictors. Significantly more variance in distress was accounted for once the strategies were added to the model, $F$ change $(8,194)=8.47, p<.001$. The same pattern of effects was observed in the second analysis with CF with one important exception: CF did not share any independent variance with distress. Again, inclusion of the strategies produced a better fitting model, accounted for significantly more variance in distress, $F$ change $(8,194)=$ $9.23, p<.001$. 
Table 7. Results of two linear regression analyses on emotional distress in Study 2.

\begin{tabular}{|c|c|c|c|c|c|c|c|}
\hline & & & & & $\begin{array}{l}95 \% \text { Con } \\
\text { Inter }\end{array}$ & nce & Adj. \\
\hline & & $\beta$ & $\mathrm{t}$ & Sig. & Lower & Upper & $\mathrm{R}^{2}$ \\
\hline & Imaginative fa & & & & & & \\
\hline 1. & Sex & -.13 & -1.97 & .06 & -18.38 & .02 & \\
\hline & Events & .13 & 1.90 & .06 & -0.05 & 2.71 & \\
\hline & IF & .24 & 3.56 & $<.001$ & 0.23 & .79 & .08 \\
\hline 2. & Sex & -.09 & -1.41 & .16 & -14.40 & 2.41 & \\
\hline & Events & .16 & 2.52 & .01 & 0.35 & 2.86 & \\
\hline & IF & .15 & 2.28 & .02 & 0.04 & .58 & \\
\hline & Self-blame & .23 & 2.93 & $<.001$ & 0.48 & 2.47 & \\
\hline & Rumination & .09 & 1.01 & .31 & -0.60 & 1.85 & \\
\hline & Catastrophizing & .11 & 1.46 & .15 & -0.28 & 1.88 & \\
\hline & Other-blame & .22 & 3.27 & $<.001$ & 0.73 & 2.93 & \\
\hline & Positive refocussing & -.11 & -1.34 & .18 & -1.87 & .36 & \\
\hline & Refocus on planning & -.22 & -2.27 & .02 & -2.82 & -.20 & \\
\hline & Positive reappraisal & .11 & 1.13 & .26 & -0.54 & 1.99 & \\
\hline & Put in perspective & .03 & .36 & .72 & -0.96 & 1.38 & .29 \\
\hline & Creative fan & & & & & & \\
\hline 1 & Sex & -.15 & -2.10 & .04 & -19.62 & -.64 & \\
\hline & Events & .15 & 2.13 & .03 & .12 & 2.93 & \\
\hline & $\mathrm{CF}$ & .12 & 1.70 & .09 & -.05 & .72 & .04 \\
\hline 2 & Sex & -.09 & -1.38 & .17 & -14.57 & 2.59 & \\
\hline & Events & .17 & 2.74 & .01 & .49 & 3.01 & \\
\hline & $\mathrm{CF}$ & .05 & .75 & .45 & -.23 & .52 & \\
\hline & Self-blame & .25 & 3.20 & $<.001$ & .63 & 2.65 & \\
\hline & Rumination & .11 & 1.26 & .21 & -.44 & 2.02 & \\
\hline & Catastrophizing & .11 & 1.39 & .17 & -.32 & 1.87 & \\
\hline & Other-blame & .22 & 3.18 & $<.001$ & .68 & 2.91 & \\
\hline & Positive refocussing & -.09 & -1.07 & .29 & -.73 & .51 & \\
\hline & Refocus on planning & -.23 & -2.30 & .02 & -2.89 & -.22 & \\
\hline & Positive reappraisal & .11 & 1.06 & .29 & -.60 & 2.00 & \\
\hline & Put in perspective & .03 & .31 & .76 & -1.00 & 1.38 & .28 \\
\hline
\end{tabular}


Figure 2 represents the outcome of analyses to test for possible mediating effects of coping on the association between IF and distress. Table 8 shows details of the indirect effects observed. As this shows, although a significant positive direct effect of IF on distress is observed, the only strategy to mediate the effect was self-blame.

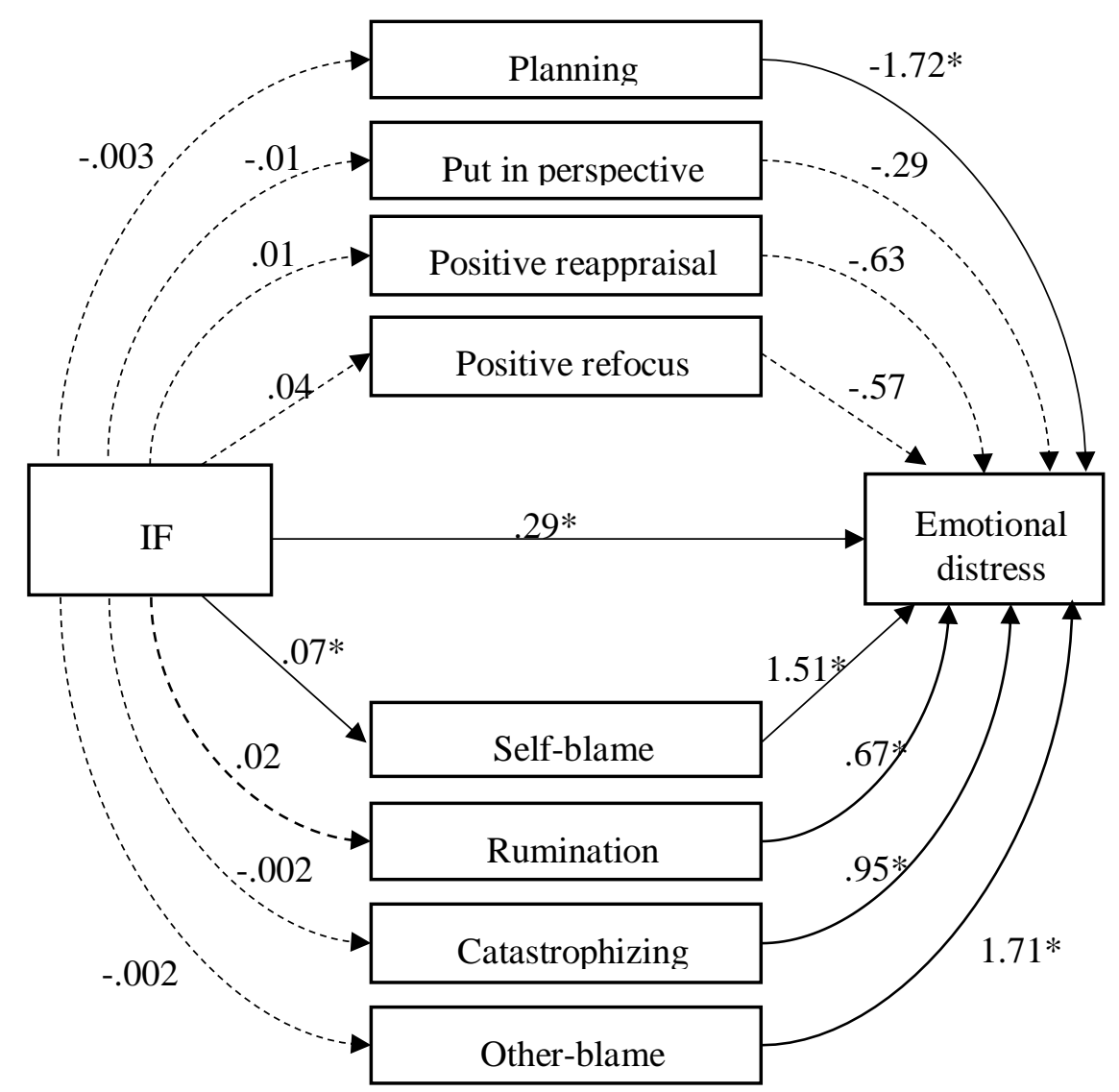

Figure 2. Mediation effects of coping strategies on the direct effect of Imaginative Fantasy on distress in Study 2. Dashed lines indicate non-significant effects. Unstandardized coefficients shown. $* \mathrm{p}<.05$ 
Table 8. Indirect effects on the association between IF and emotional distress observed in Study 2.

\begin{tabular}{llccc}
\hline & & Indirect effect & \multicolumn{2}{c}{$95 \%$ CI } \\
& Strategy & ( Unstandardized B) & lower & upper \\
\hline Adaptive strategies & Positive refocussing & -.02 & -.11 & .01 \\
& Positive reappraisal & .004 & -.01 & .06 \\
& Put into perspective & -.004 & -.06 & .01 \\
& Planning & .01 & -.05 & .07 \\
Maladaptive strategies & Self-blame & & & \\
& Rumination & .10 & .01 & .57 \\
& Catastrophizing & .01 & -.01 & .08 \\
& Other-blame & -.002 & -.06 & .03 \\
& & -.004 & -.06 & .05 \\
\hline
\end{tabular}

\section{Discussion}

Study 2 showed that different forms of fantasising are differentially associated with emotional distress. Weibel et al. (2017) highlighted the positive aspects of both Creative and Imaginative fantasy and therefore, in terms of coping, we anticipated that they would both present positive relationships with adaptive strategies and negative associations with distress. In fact, $\mathrm{CF}$ was associated positively with all strategies (adaptive and maladaptive) except for other-blame. This would therefore suggest that CF can be linked to coping, but not to emotional distress, even in the presence of maladaptive strategies. IF on the other hand also showed associations with both forms of coping, but was linked to distress. In terms of our predictions, these results do not support the idea that the two forms of fantasy are completely adaptive (Prediction 1), though that IF was positively linked to distress and to both adaptive and maladaptive strategies supports our suggestion that it represents a construct similar to original FP as measured by the CEQ (Prediction 2). Indeed a visual comparison of Tables 2 and 6 indicates a very similar pattern of correlations between FP/IF and the coping strategies.

A common link between the two studies was the mediating role of self-blame. In both cases, this strategy was linked to both fantasising and to distress and mediated an indirect 
pathway between the two. In terms of the CEQ (and most research), self-blame is considered maladaptive and there is considerable evidence to suggest its association with depression and other psychopathology (e.g. Fear et al., 2009; Ullman \& Najdowski, 2009). Our study 2 further indicated an association between self-blame and Weibel et al.'s imaginative fantasy and a link to negative emotions. Interventions to support better coping frequently focus on reducing self-blame, particularly in the context of medical diagnoses (e.g. Bennett, Compas, Beckjord \& Glinder 2005; Conradt et al., 2009). Our results suggest that such programmes might usefully consider the role that fantasy plays in perpetuating self-blame and psychopathology.

Conversely, we did not replicate Study 1 in terms of the mediating effects of rumination and positive refocussing. While these strategies were negatively and positively related to distress respectively, and both showed significant positive correlations with IF, in mediation analysis no significant path from IF was observed (see Figure 2). While we have highlighted some similarities between FP (Study 1) and IF (Study 2) above, we have no data to show the direct relationship between scores on the two scales and the extent to which they actually measure distinct constructs. Examining incremental validity in this way is desirable. It may be the case that IF is simply unrelated to these particular strategies. It is important to note that this was the first study to consider this new conceptualisation of fantasy in research and the actual nature and content of creative and imaginative fantasies generated during coping requires further study.

\section{Limitations}

This research is not without limitations, including those generally inherent in selfreport. Also, the questionnaires were completed online and given this uncontrolled research environment it could be argued that random or inattentive responding might have tainted the data. We cannot categorically rule this out. However, online platforms are now commonly 
used for psychometric research and there is evidence to suggest that the resulting data is ingenuous and reliable (Buhrmester, Kwang \& Gosling, 2011; Woods, Velascol, Levitan, Man \& Spence, 2015). The counter-intuitive finding of Acceptance being positively associated with emotional distress is unlikely to be related to inattentive responding. This was a robust finding across the two studies and has also been reported by other authors (Martin \& Dahlen, 2005). We reiterate their suggestion that further examination of Acceptance as a supposedly adaptive coping strategy is required. Another issue is that we only examined individual differences in general coping tendencies. We did not consider situational differences or actual real life events. It is entirely possible that coping strategies, the nature of fantasies, and the association between them will vary considerably in different contexts and future research might build on our novel, if preliminary, results to investigate these issues further.

In conclusion, these studies support the proposal of Klinger et al. (2009) in suggesting that fantasy proneness is a complex construct, unlikely to be unidimensional in its nature or in its association with psychopathology. We lend support to the suggestion of Weibel et al. (2017) that some aspects of fantasy can be positive and adaptive, linked to neither negative emotion nor to poor coping strategies. On the other hand, while we concur that other forms of fantasy can be associated with emotional distress and maladaptive coping as is frequently assumed, we demonstrate that this is not limited to clinical populations or to those who have experienced major trauma. Garnefski and Kraaij (2007) have suggested that therapeutically changing maladaptive coping strategies will bring about associated improvements in mental health symptoms. The present results show that fantasy proneness can also play a part in triggering emotional distress following a stressful event. Therapeutic interventions which aim to support individuals in coping effectively need to recognise that factors such as fantasy proneness can play a role in responses to stress and influence the effectiveness of coping strategies. 
RUNNING HEAD: COPING AND FANTASY

References 
Armey, M.F., Fresco, D.M., Moore, M.T., Mennin, D.S., Turk, C.L., Heimberg, R.G., ... Alloy, L.B. (2009). Brooding and Pondering: Isolating the active ingredients of depressive rumination with exploratory factor analysis and structural equation modelling. Assessment, 16, 315-327. DOI: http://dx.doi.org/10.1177/1073191109340388

Bacon, A.M., Walsh, C.E. \& Martin, L. (2013). Personality and counterfactual thinking. Personality \& Individual Differences, 54, 469-473. DOI: https://doi.org/10.1016/j.paid.2012.09.023

Bagby, R. M., Joffe, R. T., Parker, J. D. A., Kalemba, V., \& Harkness, K. L. (1995). Major Depression and the Five-Factor Model of Personality. Journal of Personality Disorders, 9, 224-234. Doi: http://dx.doi.org/10.1521/pedi.1995.9.3.224

Barrett, D. (2010). Dissociaters, fantasizers, and their relation to hypnotizability. In D. Barrett (Ed.), Hypnosis and Hypnotherapy (pp. 15-36). New York, NY: Praeger/Greenwood. Barrett (Ed.). Hypnosis and hypnotherapy (pp. 15-36). New York, NY: Praeger/ Greenwood Bennett, K.K., Compas, B.E., Beckjord, E. \& Glinder, J.G. (2005). Self-blame and distress among women with newly diagnosed breast cancer. Journal of Behavioral Medicine, 4, 313-323. DOI: http://dx.doi.org/10.1007/s10865-005-9000-0

Bigelsen, J. \& Schupak, C. (2011). Compulsive fantasy: Proposed evidence of an underreported syndrome through a systematic study of 90 self-identified non-normative fantasizers. Consciousness and Cognition, 20, 1634-1648. DOI: http://dx.doi.org/10.1016/j.concog.2011.08.013

Buhrmester, M., Kwang, T \& Gosling, S.D. (2011). Amazon's Mechanical Turk: A new source of inexpensive, yet high-quality, data? Perspectives on Psychological Science, 6, 3-5. DOI: https://doi.org/10.1177/1745691610393980

Connor-Smith, J. K., \& Compas, B. E. (2004). Coping as a moderator of relations between 
reactivity to interpersonal stress, health status, and internalizing problems. Cognitive Therapy and Research, 28, 347-368. Doi:

http://dx.doi.org/10.1023/B:COTR.0000031806.25021.d5

Conradt, M.,Dierk, J-M. Schlumberger, P., Albohn, C., Rauh, E, Hinney, A. et al. (2009). A consultation with genetic information about obesity decreases self-blame about eating and leads to realistic weight loss goals in obese individuals. Journal of Psychosomatic Research, 66, 287-295. DOI: http://dx.doi.org/10.1016/j.jpsychores.2008.09.003

Crawford, J. R., \& Henry, J. D. (2003). The Depression Anxiety Stress Scales (DASS):

Normative data and latent structure in a large non-clinical sample. British Journal of

Clinical Psychology, 42, 111-131. Doi:

http://dx.doi.org/10.1016/10.1348/014466503321903544 .

Dalenberg, C,J., Brand, B.L., Gleaves, D.H., Dorahy, M. J., Loewenstein, R.J., Cardeña, E., et al. (2012). Evaluation of the evidence for the trauma and fantasy models of dissociation. Psychological Bulletin, 138, 550-588. DOI: http://dx.doi.org/10.1037/a0027447

Dell, P. F., \& O'Neil, J. A. (2009). Dissociation and the Dissociative Disorders: DSM-V and Beyond. New York: Routledge.

Eisen, M. L., \& Lynn, S. J. (2001). Dissociation, memory and suggestibility in adults and children. Applied Cognitive Psychology, 15, 49-73. DOI:

http://dx.doi.org/10.1002/acp.834

Fear, M. Champion, J.E., Reeslund, K.L., Forehand, R. Colletti, C., Roberts, L. et al. (2009). Parental depression and interparental conflict: children and adolescents' self-blame and coping responses. Journal of Family Psychology, 23, 762-766. DOI: http://dx.doi.org/10.1037/a0016381

Folkman, S., Lazarus, R. S., Dunkel-Schetter, C., DeLongis, A., \& Gruen, R. (1986). Dynamics of a stressful encounter: Cognitive appraisal, coping, and encounter 
outcomes. Journal of Personality and Social Psychology, 50, 571-579. DOI: http://dx.doi.org/10.1037/0022-3514.50.5.992

Folkman, S. \& Moskowitz, J.T. (2004). Coping: pitfalls and promise. Annual Review of Psychology, 55, 745-774. DOI: http://dx.doi.org/10.1146/annurev.psych.55.090902.141456

Garnefski, N. \& Kraaij, V. (2007). The Cognitive Emotion Regulation Questionnaire: Psychometric features and prospective relationships with depression and anxiety in adults. European Journal of Psychological Assessment, 23, 141-149. DOI: http://dx.doi.org/10.1027/1015-5759.23.3.141

Garnefski, N. \& Kraaij, V. (2012). Effects of a cognitive behavioral self-help program on emotional problems for people with acquired hearing loss: A randomized controlled trial. Journal of Deaf Studies and Deaf Education, 1, 75-84. DOI:

http://dx.doi.org/10.1093/deafed/enr020

Garnefski N., Kraaij V., Benoist M., Bout Z., Karels E. \& Smit A. (2013). Effect of a cognitive behavioral self-help intervention on depression, anxiety, and coping selfefficacy in people with rheumatic disease. Arthritis Care \& Research, 65, 1077-1084. DOI: http://dx.doi.org/10.1002/acr.21936

Garnefski, N., Kraaij, V., \& Spinhoven, P.H. (2001). Negative life events, cognitive emotion regulation and depression. Personality and Individual Differences, 30, 1311-1327. DOI: https://doi.org/10.1016/S0191-8869(00)00113-6

Garnefski, N., van den Kommer, T., Kraaij, V., Teerds, J., Legerstee, J., \& Onstein, E. (2002). The relationship between cognitive emotion regulation strategies and emotional problems. European Journal of Personality, 16, 403-420. DOI: https://doi.org/10.1002/per.458 
Garnefski, N., Kraaij, V., \& Spinhoven, P.H. (2002). Manual for the use of the Cognitive Emotion Regulation Questionnaire. DATEC, Leiderdorp, The Netherlands.

Garnefski, N., Teerds, J., Kraaij, V., Legerstee, J., \& Van den Kommer, T. (2004). Cognitive emotion regulation strategies and depressive symptoms: differences between males and females. Personality and Individual Differences, 36, 267-276. DOI: http://dx.doi.org/10.1016/S0191-8869(03)00083-7

Gershuny, B.S. \& Thayer, J.F. (1999). Relations among psychological trauma, dissociative phenomena and trauma related distress: a review and integration. Clinical Psychology Review, 19, 631-657. DOI: http://dx.doi.org/10.1016/S0272-7358(98)00103-2

Greenwald, D.F., \& Harder, D.W. (1995). Sustaining fantasies, daydreams, and psychopathology. Journal of Clinical Psychology, 51, 719-726. DOI: https://doi.org/10.1002/1097-4679(199511)51:6\%3C719::AIDJCLP2270510602\%3E3.0.CO;2-I

Greenwald, D.F. \& Harder, D.W. (1997). Fantasies, coping behavior, and psychopathology. Journal of Clinical Psychology, 53, 91-97. DOI: https://doi.org/10.1002/jclp.10201

Hammen, C. (2005). Stress and depression. Annual Review of Clinical Psychology, 1, 293319. DOI: http://dx.doi.org/10.1146/annurev.clinpsy.1.102803.143938

Hayes, A. F. (2018). An Introduction to Mediation, Moderation and Conditional Process Analysis (2 ${ }^{\text {nd }}$ ed.). Guilford Press: New York.

Horselenberg, R., Merckelbach, H., van Breukelen, G., \& Wessel, I. (2004). Individual differences in the accuracy of autobiographical memory. Clinical Psychology \& Psychotherapy, 11, 168-176. Doi: http://dx.doi.org/10.1002/cpp.400

Kashdan, T.B., Barrios, V., Forsyth, J.B. \& Steger, M.F. (2006). Experiential avoidance as a generalized psychological vulnerability: Comparisons with coping and emotion 
regulation strategies. Behavior Research and Therapy, 9, 1301-1320. DOI: http://dx.doi.org/10.1016/j.brat.2005.10.003

Kendler, K.S., Karkowski, L.M. \& Prescott, C.A. (1999). Causal relationship between stressful life events and the onset of major depression. American Journal of Psychiatry, 156, 837-841. DOI: http://dx.doi.org/10.1176/ajp.156.6.837

Klinger, E., Henning, V. R., \& Janssen, J. M. (2009). Fantasy-proneness dimensionalized: Dissociative component is related to psychopathology, daydreaming as such is not. Journal of Research in Personality, 43, 506-510. DOI: http://dx.doi.org/10.1016/j.jrp.2008.12.017

Kluemper, N. S., \& Dalenberg, C. (2014). Is the Dissociative Adult Suggestible? A Test of the Trauma and Fantasy Models of Dissociation. Journal of Trauma \& Dissociation, 15, 457-476. doi: http://dx.doi.org/10.1080/15299732.2014.880772

Kraaij, V. \& Garnefski, N. (2015). Cognitive, behavioral and goal adjustment coping and depressive symptoms in young people with diabetes: A search for intervention targets for coping skills training. Journal of Clinical Psychology in Medical Settings 22, 45-53. DOI: http://dx.doi.org/10.1007/s10880-015-9417-8

Lazarus, R. S., \& Folkman, S. (1984). Stress, Appraisal and Coping. New York: Springer. Lovibond, S. H., \& Lovibond, P. F. (2002). Manual for the Depression Anxiety Stress Scales $\left(2^{\text {nd }}\right.$. ed. $)$. Sydney: Psychology Foundation.

Luminet, O., \& Zech, E. (2000). Predicting cognitive and social consequences of emotional episodes: the contribution of emotional intensity, the Five Factor Model, and lexithymia. Journal of Research in Personality, 34, 471-497. Doi: http://dx.doi.org/10.1006/jrpe.2000.2286

Lynn, S. J., \& Rhue, J. W. (1988). The fantasy prone personality: Hypnosis, developmental antecedents, and psychopathology. American Psychologist, 43, 35-44. 
Martin, R.C. \& Dahlen, E.R. (2005). Cognitive emotion regulation in the prediction of depression, anxiety, stress, and anger. Personality and Individual Differences, 39, 12491260. DOI: http://dx.doi.org/10.1016/j.paid.2005.06.004

Mason, M. F., Norton, M. I., Van Horn, J. D., Wegner, D. M., Grafton, S. T., \& Macrae, C.N. (2007). Wandering minds: The default network and stimulus-independent thought. Science, 315, 393-395. DOI: http://dx.doi.org/10.1126/science.1131295

Merckelbach, H. (2004). Telling a good story: Fantasy proneness and the quality of fabricated memories. Personality and Individual Differences, 37, 1371-1382. DOI: http://dx.doi.org/10.1016/j.paid.2004.01.007

Merckelbach, H., Campo, J., Hardy, S., \& Giesbrecht, T. (2005). Dissociation and fantasy proneness in psychiatric patients: A preliminary study. Comprehensive Psychiatry, 16, 181-185. DOI: https://doi.org/10.1016/j.comppsych.2004.08.001

Merckelbach, H., Horselenberg, R., \& Muris, P. (2001). The Creative Experiences Questionnaire (CEQ): A brief self-report measure of fantasy proneness. Personality and Individual Differences, 31, 987-995. DOI: https://doi.org/10.1016/S0191$\underline{8869(00) 00201-4}$

Miles, J. \& Shevlin, M. (2000). Applying Regression and Correlation: A Guide for Students and Researchers. London: Sage.

Mitchell, P.B., Parker, G.B., Gladstone, G.L., Wilhelm, K. \& Austin, M.P.V. (2003). Severity of stressful life events in first and subsequent episodes of depression: the relevance of depressive subtype. Journal of Affective Disorders, 73, 245-252. DOI: https://doi.org/10.1016/S0165-0327(01)00479-7

Muris, P., Merckelbach, H. \& Peters, E. (2003). The links between the Adolescent Dissociative Experiences Scale (A-DES), fantasy proneness, and anxiety symptoms. 
Journal of Nervous and Mental Disorders, 191, 18-24. DOI:

http://dx.doi.org/10.1097/00005053-200301000-00004

Nolen-Hoeksema, S. (1987). Sex differences in unipolar depression: Evidence and theory.

Psychological Bulletin, 101, 259-282. Doi: http://dx.doi.org/10.1037/0033-2909.101.2.259

Nolen-Hoeksema, S. (1991). Responses to depression and their effect on the duration of depressive episodes. Journal of Abnormal Psychology, 100(4), 569-582.

Nolen-Hoeksema, S., Wisko, B.E. \& Lyubomirsk, S. (2008). Rethinking rumination.

Perspectives on Psychological Science, 3, 400-424. DOI:

http://dx.doi.org/10.1111/j.1745-6924.2008.00088.x

Pine, D.S., Cohen, P., Johnson, J.G. \& Brook, J.S. (2002). Adolescent life events as predictors of adult depression. Journal of Affective Disorders, 68. 49-57. DOI: http://dx.doi.org/10.1016/S0165-0327(00)00331-1

Rauschenberger, S. \& Lynn, S.J. (1995). Fantasy proneness, DSM-III-R Axis I psychopathology, and dissociation. Journal of Abnormal Psychology, 104, 373-380.

Rauschenberger, S. \& Lynn, S.J. (2003). Fantasy-proneness, negative affect, and psychopathology. Imagination, Cognition and Personality, 22, 239-255. DOI: http://dx.doi.org/10.2190/AEXB-Y3JR-Y7T2-0A7R

Ross, C.A., Joshi, S. \& Currie, R, (1991). Dissociative experiences in the general population: A factor analysis. Psychiatric Services, 42, 297-301. DOI: http://dx.doi.org/10.1176/ps.42.3.297

Sánchez-Bernardos, M. L., \& Avia, M. D. (2004). Personality correlates of fantasy proneness among adolescents. Personality and Individual Differences, 37, 1069-1079. DOI: https://doi.org/10.1016/j.paid.2003.11.015 
Schupak, C., \& Rosenthal, J. (2009). Excessive daydreaming: A case history and discussion of mind wandering and high fantasy proneness. Consciousness and Cognition, 18, 290292. DOI: http://dx.doi.org/10.1016/j.concog.2008.10.002

Siegle, G.J., Moore, P.M., \& Thase, M.E. (2004). Rumination: One construct, many features in healthy individuals, depressed individuals, and individuals with lupus. Cognitive Therapy and Research, 28, 645-668. DOI: http://dx.doi.org/10.1023/B:COTR.0000045570.62733.9f

Smith, M. \& Mathur, R. (2009). Children's imagination and fantasy: Implications for development, education, and classroom activities. Research in the Schools, 16, 52-63.

Taylor, M., \& Carlson, S. M. (1997). The relations between individual differences in fantasy and theory of mind. Child Development, 68, 436-455. Doi: http://dx.doi.org/10.2307/1131670

Teasdale, J.D., \& Green, H.A.C. (2004). Ruminative self-focus and autobiographical memory. Personality and Individual Differences, 36, 1933-1943. DOI: http://dx.doi.org/10.1016/j.paid.2003.08.022

Tellegen, A., \& Atkinson, G. (1974). Openness to absorbing and self-altering experiences (“absorption"), a trait related to hypnotic susceptibility. Journal of Abnormal Psychology, 83, 268-277. Doi: http://dx.doi.org/10.1037/h0036681

Ullman, S.E. \& Najdowski, C.J. (2009). Correlates of serious suicidal ideation and attempts in female adult sexual assault survivors. Suicide and Life-Threatening Behavior, 39, 47 57. DOI: http://dx.doi.org/10.1521/suli.2009.39.1.47

Waldo, T.G. \& Merritt, R.D. (2000). Fantasy proneness, dissociation, and DSM-IV Axis II symptomatology. Journal of Abnormal Psychology, 109, 555-558. DOI: http://dx.doi.org/10.1037/0021-843X.109.3.555 
Weibel, D., Martarelli, C.S., Haberli, D.H. \& Mast, F.W. (2017). The Fantasy Questionnaire: A Measure to Assess Creative and Imaginative Fantasy. Journal of Personality Assessment, https://doi.org/10.1080/00223891.2017.1331913

Woods, A.T., Velascol, C., Levitan, C.L., Man, X. \& Spence, C. (2015). Conducting perception research over the internet: a tutorial review. Peer J, 3, e1058. DOI https://doi.org/10.7717/peerj.1058 